\title{
PERFILES DE PCR-RFLP EN STAPHYLOCOCCUS AUREUS METICILINA-RESISTENTES AISLADOS A PARTIR DE QUESO FRESCO ARTESANAL
}

\section{PCR-RFLP PROFILES IN METHICILLIN-RESISTANT Staphylococcus aureus ISOLATED FROM ARTISAN FRESH CHEESE}

\author{
Herrera A Fanny ${ }^{1^{*}}$, Santos B Jesús ${ }^{2}$ \\ 1 \\ Universidad de Pamplona, Facultad de Ciencias Básicas, Departamento de Microbiología, Grupo de Investigación en Microbiología y \\ Biotecnología (GIMBIO). Ciudad Universitaria, Edificio Simón Bolívar, 2do Piso. \\ Pamplona, Norte de Santander, Colombia. Correo electrónico: * fannyh@unipamplona.edu.co \\ ${ }^{2}$ Universidad de León, Facultad de Veterinaria, Departamento de Higiene y Tecnología de los Alimentos. Campus de \\ Vegazana, A.A. Nro. 24071, León, España.
}

Recibido 23 de Julio 2015; aceptado 25 de octubre de 2015

\section{RESUMEN}

Staphylococcus aureus resistente a la meticilina es en la actualidad un problema de salud pública mundial que se relaciona con infecciones intra e extrahospitalarias. El más reciente tipo de transmisión por estos microorganismos tiene que ver con la enfermedad en el hombre ocasionada por el consumo de alimentos contaminados con estas cepas. En este estudio se analizaron 11 cepas MRSA aisladas a partir de muestras de queso fresco artesanal; se establecieron los perfiles de PCR-RFLP mediante la digestión del gen coa y se compararon con algunas características fenotípicas de las cepas. La PCR-RFLP permitió discriminar entre dos cepas procedentes de la misma muestra; todas las cepas fueron $\beta$ hemolíticas y su crecimiento en Cristal Violeta fue tipo C. La presencia de cepas MRSA en las muestras de queso 
*Autor a quien debe dirigirse la correspondencia. $\quad$ E-mail: fannyh@unipamplona.edu.co analizadas pone de manifiesto el incremento en la prevalencia de bacterias multirresistentes a antibióticos que podrían tener una implicación negativa en el tratamiento de estos microorganismos en clínica; por lo anterior, se deben tomar las medidas necesarias para evitar la propagación de estas cepas a la comunidad, entre ellas la implementación de Buenas Prácticas de Manufactura en las microempresas que elaboran este producto y la supervisión en el uso de antibióticos.

Palabras clave: MRSA, PCR-RFLP, producto lácteo, resistencia antibiótica.

\section{ABSTRACT}

Methicillin-resistant Staphylococcus aureus is now a global public health problem that is related to intra and extrahospital infections. The latest type of transmission by these microorganisms has to do with human disease caused by the consumption of food contaminated with these strains. In this study, 11 MRSA strains isolated from artisanal cheese samples were analyzed; the PCR-RFLP profiles were established by digesting the coa gene and compared with some phenotypic characteristics of the strains. The PCRRFLP allowed to discriminate between two strains from the same sample; all strains were $\beta$-hemolytic and growth in Crystal Violet was type C. The presence of MRSA strains in the cheese samples analyzed reflects the increasing prevalence of multidrug-resistant bacteria to antibiotics that could have a negative implication in the treatment of these microorganisms in clinical; so It's necessary to prevent the spread of these strains in the community, including the 
Keywords: MRSA, PCR-RFLP, antibiotic resistance, dairy product.

\section{INTRODUCCIÓN}

Desde que se introdujo en los años 40 del siglo XX a la penicilina como antibiótico para tratar las infecciones por S.aureus, emergieron rápidamente cepas resistentes productoras de penicilinasas; posteriormente, en los años 50 , se dispuso de los primeros $\beta$-lactámicos estables a la acción de las penicilinasas, como la meticilina semisintética; sin embargo, en 1961 aparecieron en Inglaterra, a partir de aislamientos nosocomiales, cepas de $S$. aureus resistentes a meticilina, conocidas como MRSA. Desde entonces, las cepas MRSA se han diseminado de tal forma que hoy es el patógeno resistente más extendido del mundo (Olarte et al., 2010).

Inicialmente las cepas MRSA se limitaron al ambiente hospitalario (HA-MRSA), luego aparecieron los primeros brotes de MRSA adquiridos en la comunidad (CA-MRSA) en los cuales no existen factores de riesgo relacionados con la salud de las personas, posteriormente se reportaron MRSA en animales de abasto vivos (LA-MRSA). más reciente tipo de emergencia, tiene que ver con la enfermedad en el hombre ocasionada por el consumo de alimentos contaminados con cepas MRSA (FBAMRSA); hasta la fecha, se han reportado dos brotes de origen alimentario por estas bacterias, que han ocasionado incluso la muerte de algunos casos, siendo el origen de estos brotes, manipuladores infectados (Jones et al., 2002; Kluytmans et al., 1995). Las cepas MRSA pueden producir en el hombre desde infecciones leves en la piel hasta bacteriemia y neumonía (Jackson et al., 2013).

En todo el mundo, se ha reportado la presencia de MRSA en diversos alimentos, principalmente de origen animal; en muestras de leche en Estados Unidos (Haran et al., 2012) e Italia (Normanno et al., 2007). En Colombia se aislaron cepas MRSA a partir de muestras de carne molida y crema de leche (Vanegas et al., 2012); concretamente en queso, se ha publicado la 
presencia de cepas MRSA en muestras de queso tradicional en Irán y en Brasil (Shanehbandi et al., 2014, Fonseca et al., 2011).

Los CA-MRSA emergieron en Colombia en el 2005; en el periodo 2006 - 2007, se reportaron 15 infecciones de este tipo, con una tasa de mortalidad del $20 \%$ (Álvarez et al., 2006); los datos disponibles evidencian que los casos de MRSA adquiridos en la comunidad (CA) se incrementaron de 1,0\% en el 2001 a 5,4 \% en el 2006 (GuzmánBlanco et al., 2009); así mismo, se ha reportado una prevalencia de MRSA en hospitales de tercer nivel del $45 \%$ (Mejía et al., 2010).

Los métodos genotípicos se fundamentan en el análisis molecular de los microorganismos, principalmente en el análisis de sus ácidos nucleicos; la principal ventaja de estos métodos es su elevada capacidad discriminatoria (Tenover et al., 1995). Entre estos métodos se tiene la Reacción en Cadena de la Polimerasa acoplada a Perfiles de Restricción (PCRRFLP). La PCR-RFLP, es un método que permite clasificar bacterias a partir del patrón de bandas que se obtiene por digestión específica con una 0 varias enzimas de restricción de un fragmento previamente amplificado; se ha empleado, entre otros, para caracterizar cepas MRSA mediante los patrones de digestión del gen coa con la enzima Haell (Omar et al., 2014).

Los objetivos de este estudio fueron establecer los perfiles de PCR-RFLP del gen coa en cepas MRSA aisladas de queso fresco artesanal y compararlos con características fenotípicas de las mismas.

\section{MATERIALES Y MÉTODOS}

Cepas: Se analizaron 11 cepas de Staphylococcus meticilina-resistentes aisladas a partir de 100 muestras de queso fresco elaborado en Pamplona (Colombia). Estas cepas fueron aisladas empleando el método tradicional utilizando agar Baird Parker y realizando la prueba de la coagulasa según la NTC 4779; la detección del gen mecA se realizó mediante al procedimiento descrito en Smyth et al., (2001).

Actividad $\boldsymbol{\beta}$ - hemolítica: A partir de cultivos de cepas crecidos en caldo BHI, se realizó la inoculación en spot sobre agar sangre de oveja al $5 \%$. Se sometió a incubación a $37 \stackrel{\circ}{\mathrm{C}}$ durante 24 horas, registrando las cepas que evidenciaron la 
presencia de $\beta$-hemolisis así: amplias zonas translúcidas con bordes definidos.

Crecimiento sobre agar cristal violeta: $A$ partir de cultivos crecidos de cada cepa en agar sangre, se inocularon placas con agar Triptosa suplementado con $8 \mathrm{pg} / \mathrm{mL}$ de cristal violeta. Se realizó la incubación a $37^{\circ} \mathrm{C}$, realizando lecturas a las 24 y a las 48 horas. Se consideraron como tipo C, aquellas cepas que evidenciaron un crecimiento en spot azul o violeta con o sin un tinte naranja; como tipo $\mathrm{A}$, aquellas cepas cuyos crecimientos en spot fueron de color amarillo pálido o brillante o crecimiento de color amarillo con márgenes violeta y como tipo $E$, las cepas con crecimiento en spot de color blanco o crecimiento blanco con tono azul.

Ensayos de PCR-RFLP: A partir de las cepas crecidas en caldo $\mathrm{BHI}$ e incubadas a $37^{\circ} \mathrm{C}$ durante 24 horas, se transfirió $1 \mathrm{~mL}$, centrifugando en una microcentrífuga Eppendorf 5415D a $12,000 \mathrm{rpm} / 3 \mathrm{~min}$. Posteriormente se adicionaron $200 \mu \mathrm{L}$ de Chelex (Bio-Rad, Hercules, California, EEUU), resuspendiendo el pellet completamente e incubando a $56{ }^{\circ} \mathrm{C}$ por 30 min. Se agitó cada tubo empleando un vortex durante 10 segundos; luego se transfirió cada tubo a un bloque de calentamiento (JP Selecta S.A, Barcelona) a
$100 \stackrel{\circ}{\mathrm{C}}$ durante 8 minutos. Nuevamente se agitó cada tubo y finalmente se centrifugó a $12,000 \mathrm{rpm} / 3 \mathrm{~min}$. Se cuantificó la concentración de ADN empleando un Espectrofotómetro-UV Q3000 (Quawell, Beijing, China). Partiendo de $3 \mu \mathrm{L}$ del ADN (50 ng/ $\mu \mathrm{L}$ aproximadamente) se llevó a cabo la PCR, para esto, se amplificó el gen coa en un equipo Mastercycler Personal con las siguientes condiciones: 1 ciclo a $95^{\circ} \mathrm{C}$ por 5 min, seguido por 45 ciclos a $95 \stackrel{\circ}{\mathrm{C}}$ por $1 \mathrm{~min}, 57^{\circ} \mathrm{C}$ por $30 \mathrm{~s}$ y $72{ }^{\circ} \mathrm{C}$ por $1 \mathrm{~min}$. Se sometieron los productos de la amplificación $(5 \mu \mathrm{L})$ a electroforesis en gel de agarosa $(1 \% \mathrm{w} / \mathrm{v})$ a $100 \mathrm{~V}$ durante $1 \mathrm{~h}$. Se purificó el amplificado utilizando el kit de purificación GFX, posteriormente, se realizó la digestión de cada amplificado con $2 \mathrm{U}$ de la enzima Cfol y Alul, incubando a $37^{\circ} \mathrm{C}$ durante 6 horas. Se separaron los fragmentos digeridos en un gel de agarosa al 1,5 \% a 100 V durante 1 h. Se realizó la visualización mediante tinción con RedSafeTM (iNtRon Biotechnology, INC., Sungnam, Kyungki-Do, Korea), empleando un transiluminador de luz ultravioleta, MiniTransiluminador (Bio-Rad) y documentando con la aplicación del Digimage System acoplado a una cámara digital Canon Power Shot G11 (Major Science, Taipei, Taiwan). Finalmente se estableció el polimorfismo de la digestión del gen mediante la utilización del GelAnalyzer. 


\section{RESULTADOS Y DISCUSIÓN}

Al digerir el amplificado del gen coa con las enzimas Alu I y Cfo I, se obtuvieron dos patrones diferentes de digestión con cada enzima; con Alu I la gran mayoría de las cepas (10 cepas) arrojaron 4 fragmentos con tamaños de 206, 162, 100 y 79 bp (GelAnalyzer); con la cepa 36 se obtuvieron cuatro fragmentos de 363, 278, 193 y 143 bp (ver figura 1).

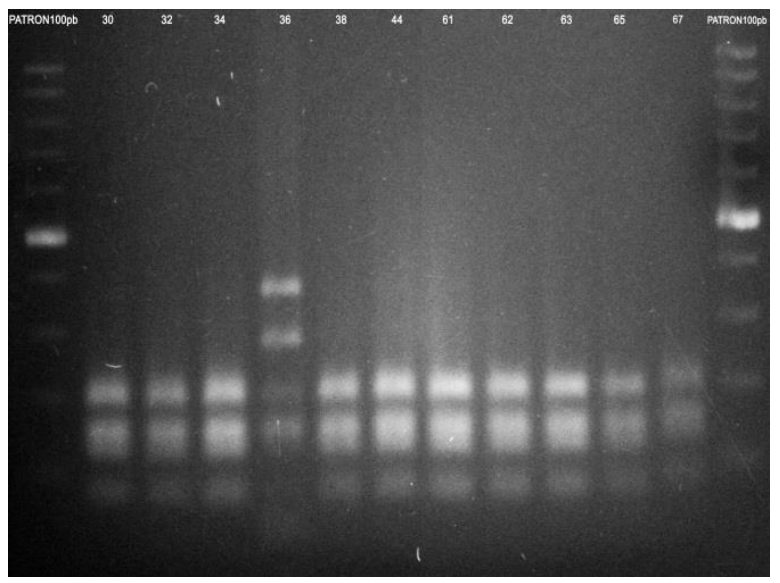

Figura 1. Patrones de RFLP obtenidos en cepas MRSA al digerir el gen coa con Alul. El patrón de peso molecular está conformado por bandas de 100 pb cada una; la banda más intensa corresponde a $500 \mathrm{pb}$.

De igual forma, la digestión con Cfo I, arrojó dos patrones de digestión que correspondieron a los obtenidos con Alu I, en el sentido que permitieron discriminar las mismas cepas, aunque los tamaños de los fragmentos obtenidos fueron diferentes por la secuencia de reconocimiento específica para cada enzima. En 10 de las cepas, se observaron dos fragmentos de 300 pb que corresponden al punto de corte de la enzima Cfo I para el gen coa; con la cepa 36 se obtuvieron cinco fragmentos de 319 , $311,206,151$ y 45 pb (ver figura 2).

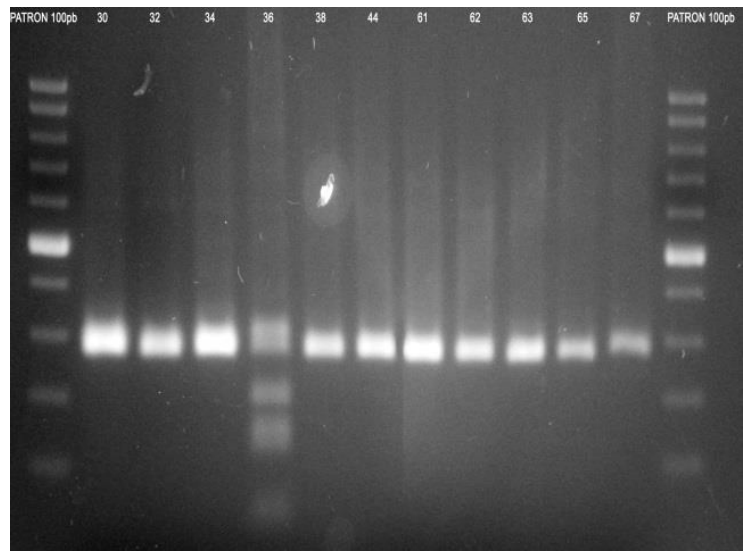

Figura 2. Patrones de RFLP obtenidos en cepas MRSA al digerir el gen coa con Cfo I.

El patrón de peso molecular está conformado por bandas de 100 pb cada una; la banda más intensa corresponde a $500 \mathrm{pb}$. Los fragmentos obtenidos en los RFLP con cada una de las enzimas, coinciden con los puntos de corte conseguidos al emplear la herramienta Unipro Ugene en los genes secuenciados. Además, es interesante destacar la discriminación que permitió esta técnica entre dos cepas aisladas a partir de la misma muestra, cepas 34 y 36 (ver tabla 1). Otros autores emplearon esta técnica 
permitiendo discriminar cepas MRSA aisladas de leche de vaca con mastitis (Moon et al., 2007).

Todas las cepas fueron $\beta$-hemolíticas y su crecimiento en cristal violeta fue de tipo $C$ (ver tabla 2), no existiendo relación con los perfiles de PCR-RFLP obtenidos en las cepas. Un estudio previo demostró que el $100 \%$ de estas cepas evidenció actividad maltosa, termonucleasa, factor de aglutinación y coagulación del plasma de conejo, corroborando así su uniformidad desde el punto de vista fenotípico; de igual forma, el mencionado estudio, puso en evidencia el potencial enterotoxigénico de estas cepas (Herrera y Santos, 2015).

Es posible que el origen de cepas MRSA en alimentos de origen animal corresponda al momento del sacrificio, ordeño o durante el proceso de elaboración del alimento siendo los manipuladores la principal fuente de contaminación (WEESE et al., 2010); así mismo, las superficies y utensilios de las microempresas de alimentos pueden ser foco de contaminación ya que se ha demostrado que cepas MRSA pueden sobrevivir, e infectar, durante varios días en diferentes fómites como madera (3 días), cerámica (21 días) y plástico (56 días) (DESAl et al., 2011).
Concretamente, la presencia de MRSA en las muestras de queso analizadas puede provenir de los manipuladores de este alimento; en un estudio realizado anteriormente por los autores se lograron comprobar las deficientes condiciones higiénico-sanitarias de los manipuladores del queso artesanal, ya que algunos de ellos presentaban heridas y laceraciones en las manos expuestas en contacto directo con el alimento y en quienes los recuentos de $S$. aureus de frotis de manos fueron elevados (DAZA et al., 2013).

Tabla 2. Caracterización de las cepas MRSA aisladas de muestras de queso fresco artesanal.

\begin{tabular}{cccccc}
\hline MUE & CE & CRECI & $\beta^{-}$ & PAT & PAT \\
\hline 37 & 30 & C & POS $^{1}$ & A & A \\
42 & 32 & C & POS & A & A \\
43 & 34 & C & POS & A & A \\
43 & 36 & C & POS & B & B \\
44 & 38 & C & POS & A & A \\
50 & 44 & C & POS & A & A \\
78 & 61 & C & POS & A & A \\
78 & 62 & C & POS & A & A \\
78 & 63 & C & POS & A & A \\
82 & 65 & C & POS & A & A \\
84 & 67 & C & POS & A & A \\
\hline
\end{tabular}

1: POS: Positivo 


\section{CONCLUSIONES}

La presencia de cepas MRSA en las muestras de queso analizadas corrobora el hecho de que bacterias multirresistentes frente antibióticos lleguen al hombre por medio del consumo de alimentos; por esta razón se deben tomar las medidas necesarias para evitar la propagación de estas cepas a la comunidad, entre ellas la implementación de Buenas Prácticas de Manufactura en las microempresas que elaboran este producto y la supervisión técnica de la administración de antibióticos durante la producción animal.
Se encontraron dos perfiles de PCR-RFLP tanto con Alu I como con Cfo I en cepas MRSA procedentes de queso fresco artesanal, no existiendo relación con los resultados de las pruebas fenotípicas realizadas a las cepas.

\section{REFERENCIAS BIBLIOGRÁFICAS}

APHA, AWWA, WPCP. Métodos normalizados para el análisis de aguas potables y residuales. 2000.

Arguello, M. Dueñas Y. \& Rojas D. (2004) Extracción y tratamiento enzimático del almidón para la obtención de dextrinas y jarabe de glucosa. Trabajo de grado para optar al título de Químico en Alimentos. Tunja. 2004.

Gonzales, Griselda, et al. (2006). Uso del exudado gomoso por Samanea saman en la potabilización de las aguas. Revista Técnica de la Facultad de Ingeniería
Universidad del Zulia. Vol 29, 226 - 231. 2006.

Molano, L. (2011). Las semillas de Moringa Oleífera Lam. Como alternativa coagulante natural para la purificación de agua. Tesis de especialista, Universidad Industrial de Santander, Bucaramanga, Colombia. 2011.

Mora M. Y Pita Y. (2006). Extracción y caracterización fisicoquímica y funcional del almidón de malanga, cultivada en el Municipio de Miraflores. Trabajo de grado para optar al título de Químico de Alimentos. Tunja. 2006. 
Wang $Y$ and Wang L. (2003).

Ochoa, J. Obtención de floculantes no iónicos y aniónicos (densidad de carga 40\%) por polimerización en microemulsión inversa, influencia del sistema tensioactivo. Revista Iberoamericana de Polímeros. Vol 4, 1416. 2003.

Robles M. (2012) Relación entre algunas propiedades fisicoquímicas y térmicas de gelatinización y retrogradación en almidón de papa nativa de Chiloé. Trabajo de grado para optar al título de Ingeniero en Alimentos. Valdivia. 2012.

Rodríguez, M. (2007). Evaluación del proceso de la coagulación para el diseño de una planta potabilizadora. Revista UMBRAL. Vol 20, 8-17. 2007.

Singley, J. (1986). Revisión de la teoría de coagulación del agua. Gainesville: Universidad de la Florida. 1986.

Vázquez, O. (1994). Extracción de coagulantes naturales del Nopal y aplicación en la clarificación de aguas superficiales. Tesis de especialista en Ingeniería Ambiental. Universidad Autónoma de Nuevo Colon, Monterrey, México. 1994.
"Physicochemical properties of common and waxy corn starches oxidized by different levels of sodium hypochlorite", Carbohydrate Polymers., vol. 52, pp. 207-217.2003. 